\title{
EL PAPEL DE LA BAHÍA DE MAZARRÓN (MURCIA) EN LOS CONTACTOS COMERCIALES MEDITERRÁNEOS EN ÉPOCA ROMANA
}

\author{
Iwona Modrzewska-Pianetti ${ }^{1}$
}

https://doi.org/10.18778/8220-421-6.18

\begin{abstract}
For many years I have dedicated myself to the study of commercial contacts between the Roman provinces, based on research on amphorae. The knowledge of the production of the amphorae of Baetica and the deposits of the amphorae of Galia Cisalpina made it possible to draw conclusions about commercial contacts between these provinces. The aim of my new study of amphorae from Mazarrón Bay (Murcia), funded by the NCN - National Science Centre in Poland, arose from my previous research. Thanks to the collaboration of the University of Murcia, the Archaeological Museum of Murcia and the Municipal Archaeological Museum of the "Factoría Romana de Salazones" of Mazarrón, I was able to document the hitherto unpublished amphorae of the Mazarrón coast. During the process of documenting 574 amphorae, excavated in the dredging works in Puerto de Mazarrón, in the stores of the Museum of Murcia and the Museum of Mazarrón,
\end{abstract}

1 Uniwersytet Warszawski, Instytut Archeologii, ul. Krakowskie Przedmieście 26/28, Warszawa 00-927, iwonamodrzewska@poczta.onet.pl; quería dar las gracias por la revisión científica a María Martínez Alcalde, directora del Museo Arqueológíco Municipal "Factoria romana de salazones", Mazarrón, España, y a la profesora Zuzanna Jakubowska-Vorbrich de la Universidad de Varsovia. 
I registered 169 containers coming from the production of the south coast of the region of Murcia. The typological and chronological elaboration, as well as the comparison with the finds of amphorae in the interior of the Mazarrón area, allow conclusions to be drawn about the local production and imports of containers from other regions of the Iberian Peninsula and from other Mediterranean areas. The study, based on pieces of material culture, allows the reconstruction of the role of Mazarrón Bay in the ancient trade of the peninsular southeast and other Mediterranean areas.

Keywords: Gulf of Mazarrón, amphorae, local spatheia, imports, ancient trade.

Palabras clave: Bahía de Mazarrón, ánforas, spatheia locales, importaciones, comercio antiguo.

Aquí presento algunos resultados de mis investigaciones financiadas por el Centro Nacional de Ciencia en Polonia. Estos estudios se basan en las ánforas halladas en la Bahía de Mazarrón, hasta la actualidad inéditos (Modrzewska-Pianetti, 2019), cuyo material anfórico se encuentra en dos museos de la Región de Murcia (Fig. 1). 


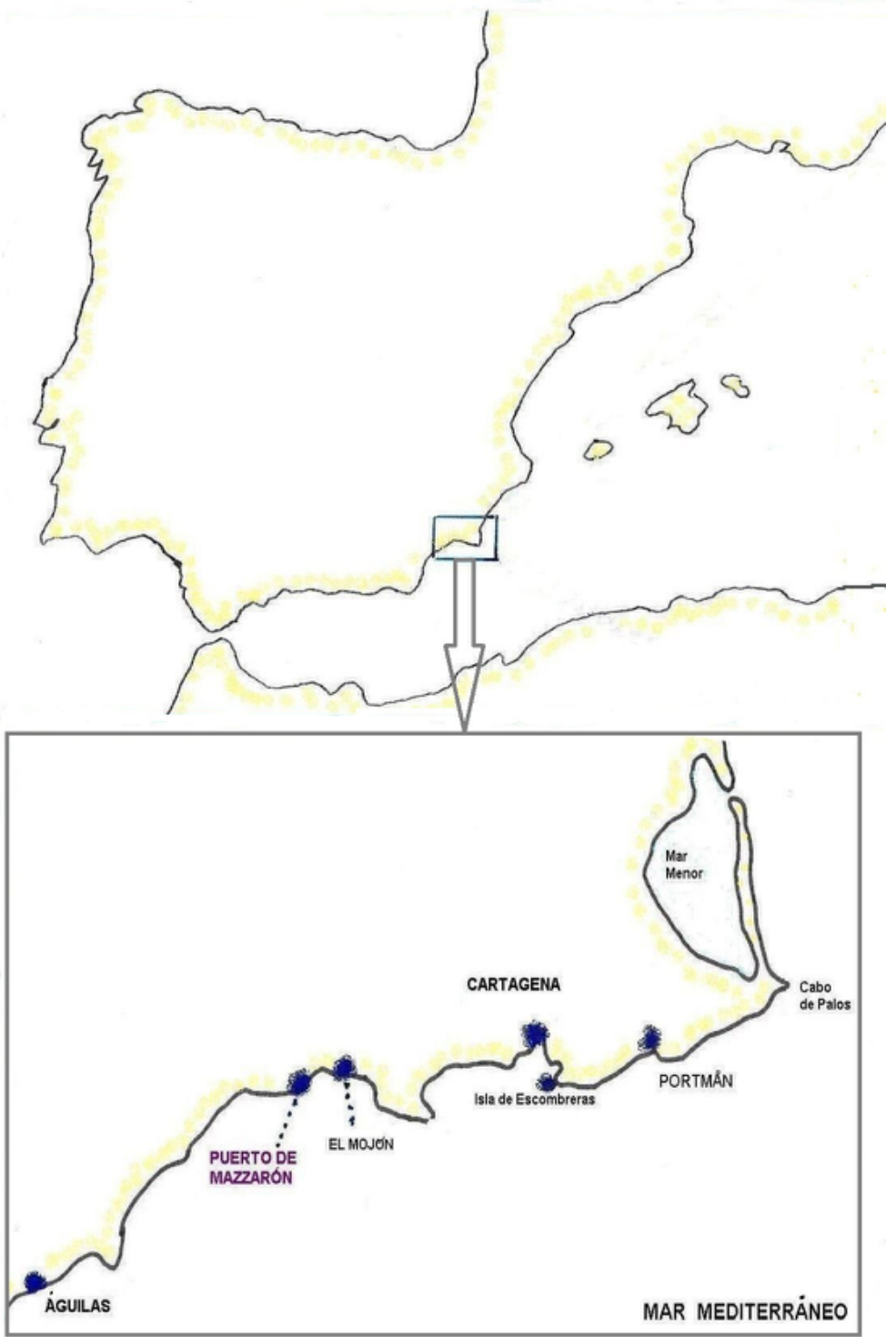

Fig. 1. Dibujo I. Modrzewska-Pianetti

El papel de la Bahía de Mazarrón (Murcia) en los contactos comerciales... 


\section{1.}

\section{Método}

Durante la documentación de las ánforas en los almacenes del Museo Arqueológico de Murcia y del Museo Arqueológico Municipal de la "Factoría Romana de Salazones" de Mazarrón he seleccionado 574 ánforas, localizadas en los trabajos de los dragados en el Puerto de Mazarrón (Fig. 2).

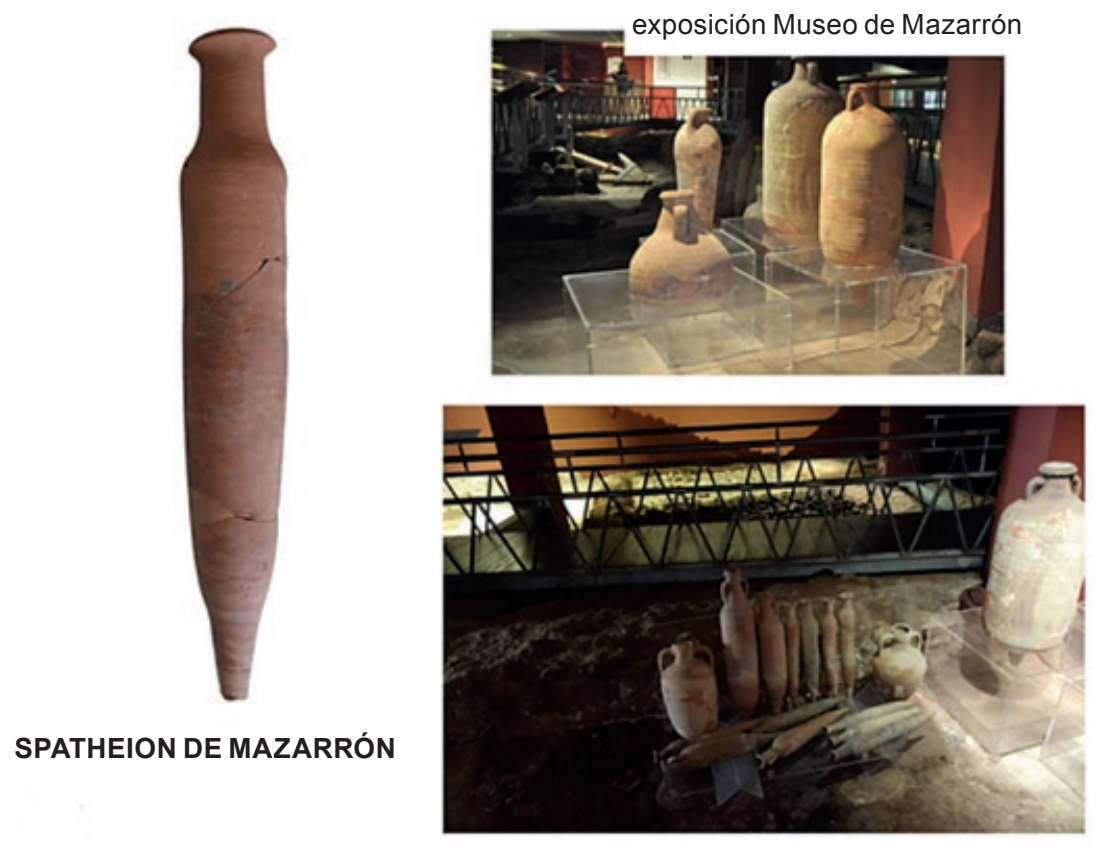

Fig. 2. Fot. I. Modrzewska-Pianetti

En este numeroso grupo he registrado 169 contenedores procedentes de la producción de la costa sur de la Región de Murcia. Para las producciones de la costa murciana me han servido publicaciones de María Martínez Alcalde y el doctorado de María Berrocal Caparrós dedicado a las producciones de El Mojón, incluidas las de Puerto de Mazarrón, El Castellar, La Azohía y Águilas, desde el siglo IV hasta finales del siglo VI d.C. (Martínez Alcalde, 2004; Martínez Alcalde, 2019; Berrocal Caparrós, 2007; Berrocal Caparró, 2012, Fig. 3). 


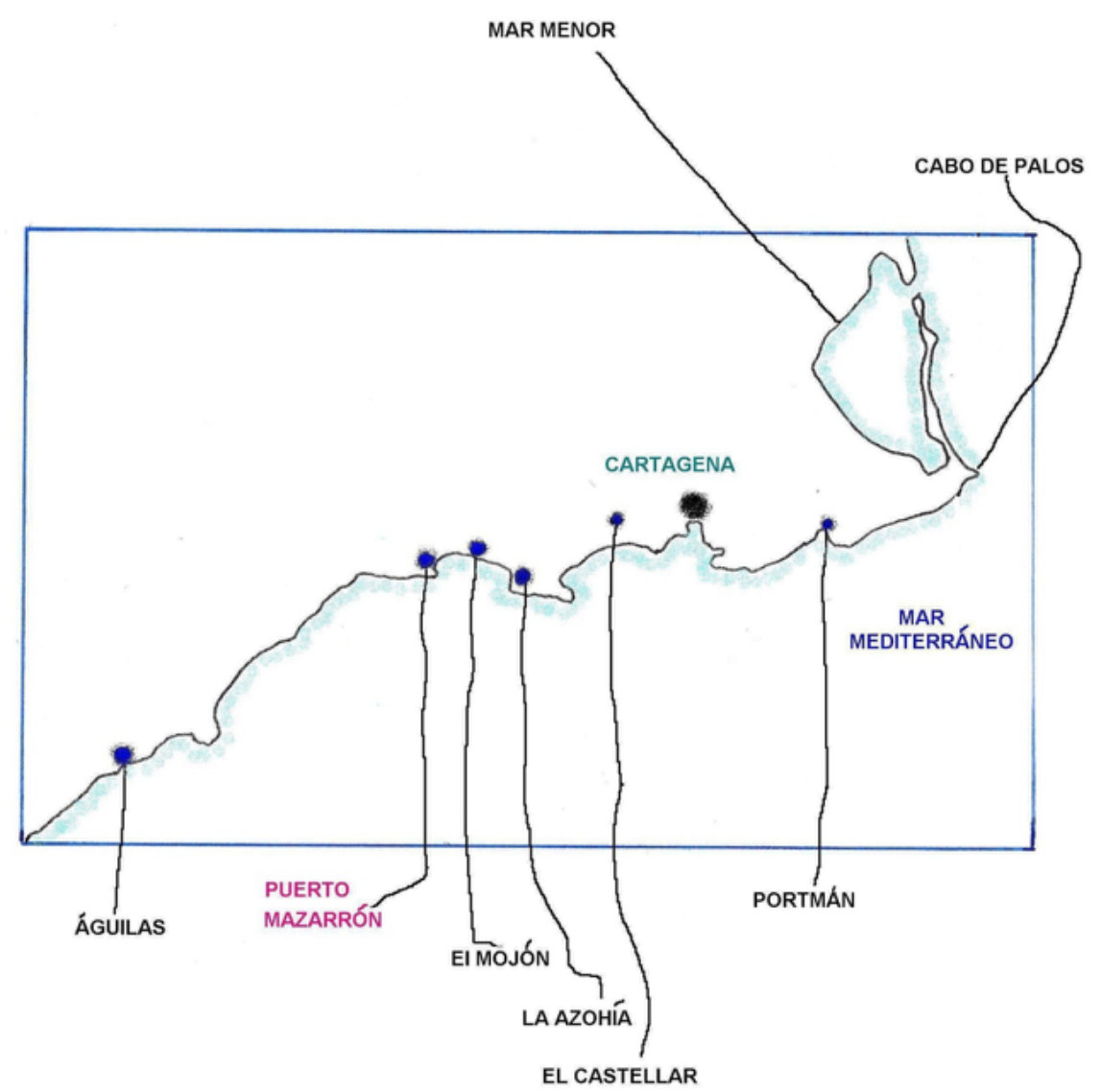

Fig. 3. Dibujo I. Modrzewska-Pianetti

\section{2. \\ Ánforas}

De la producción local, es característica la forma de spatheia (ánfora fusiforme), aunque el yacimiento de El Mojón tenía mayor repertorio de imitaciones de formas africanas y de formas de Matagallares en Granada e imitaciones de contenedores lusitanos (Berrocal Caparrós, 2012:259-270, Fig. 4). 


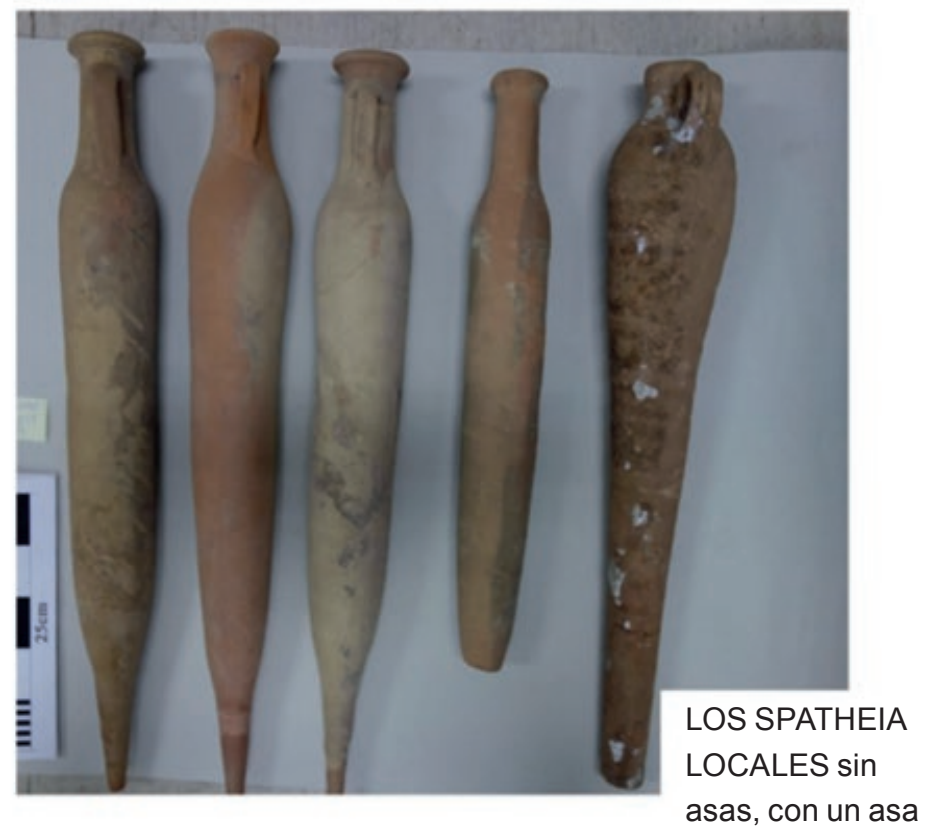

UN ASA PERFORADA TIPO EL MOJÓN

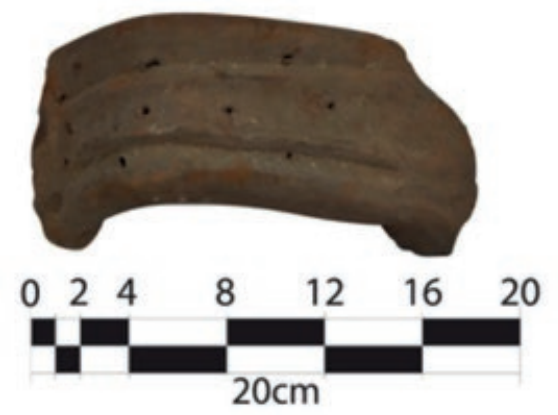

Fig. 4. Fot. I. Modrzewska-Pianetti 
Estas ánforas locales servían para las salsas y conservas de pescado producidas en factorías locales descubiertas entre el puerto de Cartagena y Águilas situadas en la costa sur de la región (Martínez Alcalde 2019). En los hallazgos de ánforas de producción local procedentes de la Bahía de Mazarrón dominan formas producidas en El Mojón, siendo más de $66 \%$ del total. Este taller funcionó desde el siglo IV hasta los principios del siglo VII d.C. Las ánforas de El Mojón fueron reconocidas con cierta probabilidad en Tarraco, Hispalis y en los niveles tardíos en Cartagena de mediados del siglo VI d.C., en la factoría de salazones de Portus Ilicitanus y Lucentum (Berrocal Caparrós, 2012: 271-272). La distribución de spatheia puede indicar el transporte de contenedores vacíos a las factorías de salazones a lo largo de la costa. Los hallazgos en la Bahía de Mazarrón responden a conjuntos accidentales creados entre el siglo IV y principios del siglo VII d.C. probablemente durante labores del transbordo de mercancías. Los hallazgos de los dragados del siglo XX muestran la diversidad de las importaciones de los contenedores (Agüera Martínez, 2004). El motivo de la acumulación de los hallazgos también puede ser debido al abandono de las ánforas para deshacerse del lastre durante las tormentas. En la costa francesa, en el estrecho de Bonifacio y en la costa alicantina se conocen naufragios con productos béticos (Liou, 2001: 1066; De Juan Fuertes, Cibecchini, Ventó, 2011; Ramallo Asensio, Martínez Andreu, 2010). Las condiciones geomorfológicas de la Comunidad Valenciana han sido bien investigadas, lo que permite apreciar los hallazgos subacuáticos de la costa de Dénia (Carmona Gónzalez, Ruiz Pérez, 2003).

\section{3. \\ La Costa de Mazarrón}

La costa de Mazarrón tiene condiciones naturales favorables para la navegación. Su litoral ha cambiado a lo largo de los siglos bajo la influencia de la dinámica de la sedimentación, y así se crearon las salinas características de dicha área (Dabrio, Polo, 
1981). Las costas de Mazarrón y Águilas son espacios deprimidos topográficamente, surcados por grandes ramblas que sirven a la vez de paso fácil hasta el corredor del río Guadalentín (Berrocal Caparrós, Pérez Ballester, 2010: 45-47). Las amplias bahías de Mazarrón y Águilas con islas frente a la costa favorecen contactos marítimos. Las buenas condiciones naturales de Mazarrón fomentaron la colonización desde la Edad de Bronce, aunque tampoco faltan los testimonios anteriores (García Jorquera, 2004; Iniesta Sanmartín, 2004). Los depósitos de metales en las sierras mineras de Cartagena y de Mazarrón hicieron que los barcos fenicios atracaran en la costa a partir de la segunda mitad del siglo VII a.C., según lo confirmado por los hallazgos en la Bahía de Mazarrón (Guil Cid, 2004; Martínez Alcalde, 2017; Mauro, 2014).

\section{4. \\ Ánforas importadas}

Desde el siglo IV a.C. llegaron allí las ánforas grecoitálicas de Magna Grecia e itálicas de la costa tirrena y adriática encontradas en la costa mazarronera como en el complejo del Alamillo (Martínez Mañogil, 2015: nota 7). Los naufragios con ánforas itálicas entre la isla de Escombreras, San Ferreol y las Islas Baleares confirman esta dirección de los contactos desde el período de la República (Asensio i Villaró, 2010; Roldán Gómez, 1990: 137-142). Las ánforas grecoitálicas presentes en varios contextos en Hispania Citerior, Ulterior y en Cartagena representan un porcentaje significativo de hallazgos de los mediados del siglo I a.C. (Molina Vidal, 1997, Fig. 46; Molina Vidal, 1999; Pérez Ballester, 2009; Corredor, 2016: 263-280). En los hallazgos al sur del Cabo de Nao hay tantas ánforas adriáticas para el vino, como tirrenas (Pérez Ballester, 2009: 560). 
Tabla 1. Los porcentajes de ánforas de diferentes procedencias en relación con su número total (sin 169 ánforas locales)

\begin{tabular}{lr|c}
\multicolumn{1}{c|}{ PROCEDENCIA } & CANTIDAD & PORCENTAJES \\
Italia & 51 & 12,59 \\
\hline Narbonense & 4 & 0,99 \\
\hline Egeo y Oriente & 18 & 4,44 \\
\hline África septentrional & 102 & 25,19 \\
\hline Lusitania & 21 & 5,18 \\
\hline Ibiza & 6 & 1,48 \\
\hline Tarraconense & 14 & 3,46 \\
\hline Bética & 189 & 46,67 \\
\hline
\end{tabular}

En los hallazgos costeros son numerosas también las ánforas egeas, lo que puede sugerir que todas las piezas iban juntas en un solo transporte (Pérez Bonet, Cabrera Bonet, 1992: 501). Durante el siglo II y I a.C. aparecen ánforas para aceite de Brindisi y la forma llamada africana antigua. Después de las imitaciones de ánforas grecoitálicas, a partir del siglo I a.C., empiezan a fabricarse las imitaciones béticas y tarraconenses de ánforas de Italia, aunque su propósito podría ser bivalente (García Vargas, 2004, Fig. 5). En los siglos siguientes, a la costa de Mazarrón llegaron las ánforas de Italia de Forlimpopoli y Empoli y luego de Calabria. Excepcional es un ejemplar de la llanura Padana, que llegó a la costa probablemente junto con las ánforas de Forlimpopoli. Desde finales del siglo II hasta el siglo I a.C. en los hallazgos de la costa de Mazarrón, las más comunes son las ánforas de Bética, incluidas las formas ovoidales del valle del Guadalquivir, para aceite y el defrutum (García Vargas, De Almeida, González Cesteros, 2011; García Vargas, Bernal Casasola, 2008). Desde finales del siglo I a.C. hasta el siglo II d.C. las ánforas clásicas béticas Dressel 7-11 y otros tipos usados para salazones, incluidas Dressel 20 para aceite, constituyen la mayoría de los hallazgos. Además, llegaron a la costa de Mazarrón las ánforas del taller de Los Matagallares en Granada y las imitaciones africanas de Puente Melchor en Cádiz, datadas del siglo IV al V d.C. (Bernal Casasola, 1998; Bernal Casasola, 
2001; Millán León, Lavado Florido, 2001). La cantidad de ánforas béticas y tarraconenses que imitan a formas gálicas excede la importación de Galia Narbonense (Tab. 1). En los hallazgos de Mazarrón hay pocas importaciones de Tarraconense y la mayor cantidad de imitaciones son ánforas para vino de los siglos I hasta III d.C. Las ánforas lusitanas de los siglos I al V d.C. constituyen más del 5\% del total en los hallazgos de la costa de Mazarrón. Hay otros contenedores lusitanos custodiados en el Museo de Arqueología Subacuática (ARQUA) en Cartagena (Quevedo, Bombico, 2016: 312-314). Dichas ánforas son contenedores para salazones, conocidos también de pecios tardorromanos del Mediterráneo, como Cabrera III en Baleares, Rondello al sur de Sicilia y otros (Bost, Campo, Colls, 1992; Mayet, 2001: Fig. 3).

\section{5. \\ El papel de Puerto de Mazarrón}

El estado de la investigación de los materiales de Mazarrón nos permite realizar comentarios sobre el significado de la costa que resultan muy importantes para el sureste peninsular. De las excavaciones en el vertedero formado en la segunda mitad del siglo IV e inicios del V d.C., y más tarde de la necrópolis localizada en este lugar, en la calle San Vicente en el Puerto de Mazarrón, vienen las ánforas lusitanas, norteafricanas, orientales y locales de los siglos entre el V y el inicio del VII d.C. (Pérez Bonet, 1992). Un conjunto similar pero no idéntico de ánforas proviene del vertedero del siglo V d.C. del Cine Serrano en la calle Cartagena, donde aparecen las ánforas norteafricanas, y en cantidad menor, contenedores lusitanos y béticos, como también numerosas spatheia locales (Amante Sánchez, 1989). Se puede observar la disparidad entre el gran número de ánforas de los hallazgos en la dársena de Mazarrón y las pequeñas cantidades extraídas durante los trabajos terrestres (Amante Sánchez, 1989: 222). Parece que el Puerto de Mazarrón no sólo ha sido el centro receptor, sino también distribuidor de productos llegados a la costa. La necrópolis llamada La Molineta 
en la ciudad tiene una serie de entierros que demuestran la intensa ocupación del territorio entre los siglos IV hasta V d.C. por la población dedicada a la producción de salazones y la manufactura de la sal (Amante Sánchez, García Blánquez, 1988). En ocasiones, algunas ánforas se reutilizaron para enterramientos en fechas del tránsito entre los siglos IV y V d.C. Ánforas locales fueron encontradas en la zona de los baños romanos en la calle Cartagena en Mazarrón (Agüera Martínez, Iniesta Sanmartín, 1994: 316) y en sucesivas etapas de uso han sido encontradas ánforas norteafricanas, lusitanas y spatheia. En la calle Fábrica en el Puerto de Mazarrón fueron descubiertas las estructuras del yacimiento industrial en conexión con la factoría de salazones, donde al lado de fragmentos de ánforas lusitanas se encontraron ánforas locales (Pérez Bonet, 1989: 240; Martínez Alcalde, Iniesta Sanmartín, 2007: 57-59). En la calle Era en Mazarrón se descubrieron los restos de una casa romana que data de los siglos IV hasta V d.C. y también se asocia con el cercano puerto y la industria de salazones (García Sandoval, 2006; Martínez Alcalde, 2004). Los ejemplos mencionados de los hallazgos terrestres indican que pequeñas cantidades de ánforas norteafricanas coexisten con las spatheia de producción local que empiezan a dominar desde el siglo IV d.C. El Puerto de Mazarrón estaba incluido en el círculo de producción de salazones como también, por ejemplo, en la isla de Fraile (Aguilas), las producciones de ánforas en El Mojón y La Azohía, y las producciones de Águilas (Ramallo Asensio, 1985; Berrocal Caparrós, 2012: 259: Fig. 1)., que estaban destinadas para el consumo local, pero también, como lo demuestran los hallazgos en la Bahía de Mazarrón, han sido transportadas a lo largo de la costa.

\section{6. \\ Hallazgos de las ánforas}

Esto confirma el tipo de ánforas del pecio de Cala Reona de siglo V d.C., descubierto cerca de la costa murciana (Pérez Rebollo, 1989: 646-647; Pinedo Reyes, Pérez Bonet, 1991: 404: Fig. 7 
derecha). Un ánfora del tipo El Mojón de la costa de Mazarrón estaba cerrada con tapón de cal. En los hallazgos en la Boca Chica de Escombreras, junto con ánforas itálicas, varias béticas y norteafricanas, se encontraron unas procedentes de El Mojón (Alonso Campoy, Pinedo Reyes, Miñano Domínguez, Gómez Bravo, 1996: Fig. 4 ESC/96/02). Las mercancías en ánforas norteafricanas llegaban en masa a la costa de Mazarrón, apareciendo una pequeña proporción de material procedente del Mediterráneo oriental. Deben ser reconocidos como muy enriquecedores los trabajos en la calle de la Cuesta de la Baronesa en Cartagena, donde se encontró un almacén de las ánforas preparadas para llenar con productos de salazones del período entre el siglo I y los comienzos del siglo II d.C. (Martín Camino, Roldán Bernal, 1997: 210-211). Este descubrimiento proporciona nueva información sobre el uso de ánforas en esta área.

Mi investigación evidencia que entre los hallazgos de la Bahía de Mazarrón hay muchos tipos de ánforas de importación con una cronología desde el siglo IV a.C. hasta principios del siglo VII d.C. de diferentes procedencias. El comercio de la costa mazarronera no termina con las invasiones vándalas, dominaciones bizantina y visigoda. La enumeración de la cantidad de bienes importados en este caso no parece poder realizarse con mucha precisión debido al uso polivalente de ánforas, especialmente de las ánforas béticas y norteafricanas. Estas norteafricanas constituyen más de $20 \%$ del total. Las ánforas norteafricanas registradas en la estratigrafía del teatro romano de Cartagena, espacio después reutilizado como mercado, y en los hallazgos de la Bahía de Mazarrón están presentes desde el siglo IV hasta principios del siglo VII d.C. (Remolà Vallverdú, 2000: 218, 235; Ramallo Asensio, Ruiz Valderas, Berrocal Caparrós, 1996: 184). En la costa de Mazarrón, se identificaron ánforas de los siglos II al IV d.C., principalmente de la región de Nabeul en Túnez, y solo dos ejemplares de Tripolitania (Mrabet, 2004: 4). Hay pocas importaciones orientales en la costa de Mazarrón en comparación con las ánforas norteafricanas, como en los contextos de Cartagena.

Todos los materiales estudiados procedentes del agua y confrontados con los hallazgos terrestres demuestran que la costa de 
Mazarrón fue un punto de desembarco muy importante, porque la cantidad de bienes que llegaron aquí probablemente excedía las necesidades de la población local. Las relativamente pequeñas cantidades de ánforas encontradas en la tierra contrastan con las grandes cantidades de ánforas encontradas en el agua. Los hallazgos sueltos de la costa no se pueden tratar como un efecto de cambios históricos que ocurrirían en el territorio desde el siglo $\mathrm{V}$ hasta el comienzo del siglo VII d.C. Estos cambios se registraron en la estratigrafía de Cartagena (Reynolds, 2011: 104-105, 109-113).

\section{7.}

\section{Conclusiones}

Mi estudio es una documentación de piezas cuyo significado puede explicarse durante la investigación subacuática y por el estudio de la relación entre los talleres de producción de la costa y el interior. Queda por explicar por qué las ánforas de la Bahía de Mazarrón solo se conservan fragmentadas. Tal vez el trabajo de la construcción del puerto de Mazarrón en el siglo XIX afectara al estado de conservación de las ánforas (Berrocal Caparrós, Lopez Rosique, 2003) o ¿quizá fuera el resultado de la destrucción durante los dragados del siglo pasado? La cantidad de ánforas datadas del período entre el siglo IV a.C. y los principios del siglo VII d.C. extraída de las aguas de la Bahía de Mazarrón demuestra la importancia de este área para el intercambio comercial de la costa sur de la Región de Murcia con otras áreas del Mediterráneo y la importancia de la producción local para las salazones de las factorías ubicadas en la costa de la Bahía.

\section{Bibliografía}

Agüera Martínez, S. (2004): "Los hallazgos arqueológicos de la dársena de Puerto de Mazarrón”, en: Carlantum: Actas I Jornadas de Estudio sobre Mazarrón, S. Agüera Martínez, J. García 
Jorquera, F. Guil Cid, A. Iniesta Sanmartín, M. Martínez Alcalde (eds.). Mazarrón: Universidad Popular: 9-45.

Agüera Martínez, S., Iniesta Sanmartín, A. (1994): “Actuaciones arqueológicas en la calle Cartagena del Puerto de Mazarrón. Las termas romanas de la calle Cartagena". Memorias de Arqueología, 9: 301-327.

Alonso Campoy, D., Pinedo Reyes, J., Miñano Domínguez, A.I., Gómez Bravo, M. (1996): "Prospecciones submarinas de urgencia en la Boca Chica de Escombreras, Cartagena (1996)”. Memorias de Arqueología, 11: 411-422.

Amante Sánchez, M. (1989): "El vertedero romano-tardío del cine Serrano c/ Cartagena (Puerto Mazarrón, Mazarrón, Murcia). Noticia preliminar". Memorias de Arqueología, 4: 217-223.

Amante Sánchez, M., García Blánquez, L.A. (1988): "La necrópolis tardorromana de La Molineta, Puerto Mazarrón (Murcia), calle Sta. Teresa, núm. 36-38”. Antigüedad y Cristianismo, 5:449-470. Asensio i Vilaró, D. (2010): "El comercio de ánforas itálicas en la Península Ibérica entre los siglos IV y I a.C. y la problemática en torno a las modalidades de producción y distribución". Bollettino di Archeologia on line vol. speciale B/B8/3: 23-41 [10.09.2018].

Bernal Casasola, D. (1998): "Las producciones anfóricas del taller", en: Los Matagallares (Salobreña, Granada). Un centro romano de producción alfarera en el siglo III d.C. Primeros resultados de las excavaciones arqueológicas de las campañas de 1995 y 1996, D. Bernal Casasola, J.A. Navas (eds.). Salobreña: Ayuntamiento: 233-305. Bernal Casasola, D. (2001): "La producción de ánforas en la Bética en el s. III y durante el Bajo Imperio Romano", en: Ex Baetica Amphorae: conservas, aceite y vino de la Bética en el Imperio Romano, Actas del Congreso Internacional (Écija y Sevilla 17-20 de diciembre de 1998), Vol. I, G. Chic García, M. Bendala Galán, F. Chaves Tristán, A. Fuentes Rodriguez (eds.). Écija y Sevilla: Universidad de Sevilla: 239-372.

Berrocal Caparrós, M.C. (2007): "Nuevas aportaciones sobre cerámicas tardías producidas en el área Carthago Spartaria: el alfar de El Mojón", en: Estudios de cerámica tardorromana y altomedieval, A. Malpica Cuello, J.C. Carvajal López (eds.). Granada: Alhulia Editoral: 291-314. 
Berrocal Caparrós, M.C. (2012): "Producciones anfóricas en la costa meridional de Carthago-Spartaria”, en: Cerámicas hispanorromanas II: producciones regionales, D. Bernal Casasola, A. Ribera i Lacomba (eds.). Cádiz: Universidad: 255-277.

Berrocal Caparrós, M.C., López Rosique, C. (2003): "Evolución portuaria del frente marítimo de Cartagena entre los siglos XVI y XX”, en: Puertos fluviales antiguos: ciudad, desarrollo e infraestructuras, G. Pascual Berlanga, J. Pérez Ballester (eds). Valencia:Universidad: 351-362.

Berrocal Caparrós, M.C., Pérez Ballester, J. (2010): “Puertos y fondeaderos de la costa murciana: dinámica costera, tipología de los asentamientos, interacciones económicas y culturales". Bollettino di Archeologia on line vol. speciale B/B6/5: 36-50, 20.12.2018.

Bost, J.P., Campo, M., Colls, D. (1992): “L'épave Cabrera III (Majorque). Échanges commerciaux et circuit monétaires au milieu du III siècle après Jésus-Christ". Paris: Publication du Centre Pierre Paris.

Carmona Gónzalez, P., Ruiz Pérez, J.M. (2003): “Cambios geomorfológicos y puertos históricos en la costa mediterránea valenciana", en: Puertos fluviales antiguos: ciudad, desarrollo e infraestructuras, G. Pascual Berlanga, J. Pérez Ballester (eds.). Valencia: Universidad: 115-126.

Corredor, D.M. (2016): Comercio anfórico y relaciones mercantiles en Hispania Ulterior (siglos II a.C.-II d.C.), [= Col-lecció Instrumenta 52]. Barcelona: Universidad.

Dabrio, C.J., Polo, M.D. (1981):“Dinámica litoral y evolución costera del Puerto de Mazarrón (Murcia)". Boletín de la Real Sociedad Española de Historia Natural (Geol.), 79:225-234.

De Juan Fuertes, C., Cibecchini, F., Ventó, E. (2011): "El pecio romano Bou Ferrer, un velero de comercio naufragado en la costa de la Vila Joiosa", en: La Vila Joiosa. Arqueologia i Museu, A. Espinosa (ed.). Alicante: Museo Arqueológico (MARQ): 89-107.

García Jorquera, J. (2004): "Mazarrón en la Prehistoria", en: Carlantum: Actas I Jornadas de Estudio sobre Mazarrón, S. Agüera Martínez, J. García Jorquera, F. Guil Cid, A. Iniesta Sanmartín, M. Martínez Alcalde (eds.). Mazarrón: Universidad Popular: 47-67. 
García Sandoval, J. (2006): “De la conservación de la presentación al público. El tratamiento de los restos de la casa romana de la Calle Era", en: Carlantum: Actas III Jornadas de Estudio sobre Mazarrón, S.F. Ramallo Asensio, S. Agüera Martínez, J. García Sandoval (eds.). Mazarrón: Universidad Popular: 245-268.

García Vargas, E. (2004): "Las ánforas del vino bético altoimperial: formas, contenidos y alfares a la luz de algunas novedades arqueológicas", en: Figlinae Baeticae. Talleres, alfareros y producciones cerámicas (siglos II a.C.-VII d.C.), Actas del Congreso Internacional, Cádiz 12-14 de diciembre 2003, L.G. Lagóstena Barrios, D. Bernal Casasola (eds.) [=BAR International Series 1266 (II)]. Oxford: University: 507-514.

García Vargas, E., Bernal Casasola, D. (2008): “Ánforas de la Bética", en: Cerámicas hispanorromanas: un estado de la cuestión, D. Bernal Casasola, A. Ribera i Lacomba (eds.). Cádiz: Universidad: 661-688.

García Vargas, E., De Almeida, R.R., González Cesteros, H. (2011): "Los tipos anfóricos del Guadalquivir en el marco de los envases hispanos del siglo I a. C. Un universo heterogéneo entre la imitación y la estandarización". Spal. Revista de Prehistoria y Arqueología, Universidad de Sevilla, 20: 185-284.

Guil Cid, F. (2004): "Los fenicios: los barcos de Mazarrón", en: Carlantum: Actas I Jornadas de Estudio sobre Mazarrón, S. Agüera Martínez, J. García Jorquera, F. Guil Cid, A. Iniesta Sanmartín, M. Martínez Alcalde (eds.). Mazarrón: Universidad Popular: 68-88.

Iniesta Sanmartín, A. (2004): "La arqueología de Mazarrón”, en: Carlantum: Actas I Jornadas de Estudio sobre Mazarrón, S. Agüera Martínez, J. García Jorquera, F. Guil Cid, A. Iniesta Sanmartín, M. Martínez Alcalde (eds.). Mazarrón: Universidad Popular: 89-99.

Liou, B. (2001): "Las ánforas béticas en el mar", en: Ex Baetica Amphorae: conservas, aceite y vino de la Bética en el Imperio Romano, Actas del Congreso Internacional (Écija y Sevilla 17-20 de diciembre de 1998), Vol. III, G. Chic García, M. Bendala Galán, F. Chaves Tristán, A. Fuentes Rodriguez (eds.). Écija y Sevilla: Universidad de Sevilla: 1061-1110. 
Martín Camino, M., Roldán Bernal, B. (1997): "Calle Cuesta de la Baronesa, calle subida de las Monjas”, Memorias de Arqueología en Cartagena 1982-1988, s.n.: 202-212.

Martínez Alcalde, M. (2004): "La Sala Arqueológica de Mazarrón y la factoría romana de salazones", en: Carlantum: Actas I Jornadas de Estudio sobre Mazarrón, S. Agüera Martínez, J. García Jorquera, F. Guil Cid, A. Iniesta Sanmartín, M. Martínez Alcalde (eds.). Mazarrón: Universiadad Popular: 100-129.

Martínez Alcalde, M. (2017): “El patrimonio arqueológico costero litoral del Mazarrón y el papel del Museo de Mazarrón como impulsor y gestor del proyectos de recuperación del patrimonio", en: Mazarrón II. Contexto arqueológico, viabilidad científica y perspectiva patrimonial del barco B-2 de la bahía de Mazarrón (Murcia). En homenaje a Julio Mas García, M. Martínez Alcalde, J.M. García Cano, J. Blánquez Pérez, A. Iniesta Sanmartín (eds.). Madrid: UAM Ediciones: 37-73.

Martínez Alcalde, M. (2019): "Spatheion en Mazarrón (Murcia, España). Las producciones locales", en: I. Modrzewska-Pianetti, J.A. Molina Gómez (eds.), Contactos comerciales de la Región de Murcia (España) con el mundo mediterráneo en la Antigüedad. Varsovia: Universidad: 29-53.

Martínez Alcalde, M., Iniesta Sanmartín, A. (2007): Factoría romana de salazones. Guía Museo Arqueológico Municipal de Mazarrón. Murcia: Ayuntamiento de Mazarrón.

Martínez Mañogil, M.C. (2015): “Aproximación a la villa romana del Alamillo (Mazarrón): nuevas perspectivas”. Verdolay, 14: 205-240.

Mauro, C.H.M. (2014): "Los pecios fenicios en Época Arcaica, estado de la cuestión”. Ab Initio, 10: 3-29.

Mayet, F. (2001): “Les amphores lusitaniennes", en: Céramiques hellénistiques et romaines III, P. Lévêque, J.P. Morel (eds.), Paris: Institut des Sciences et Techniques de l' Antiquité: 277-293.

Millán León, J., Lavado Florido, M.L. (2001): “El complejo industrial de Puente Melchor (Puerto Real, Cádiz)”, en: Ex Baetica Amphorae: conservas, aceite y vino de la Bética en el Imperio Romano, Actas del Congreso Internacional (Écija y Sevilla 17-20 de diciembre de 1998), Vol. I, G. Chic García, M. Bendala Galán, 
F. Chaves Tristán, A. Fuentes Rodriguez (eds.). Écija y Sevilla: Universidad de Sevilla: 215-225.

Modrzewska-Pianetti, I. (2019): "Las ánforas locales e importadas procedentes de la Bahía de Mazarrón", en: I. Modrzewska-Pianetti, J.A. Molina Gómez, J.A. (eds.): Contactos comerciales de la Región de Murcia (España) con el mundo mediterráneo en la Antigüedad. Varsovia: Universidad: 57-126.

Molina Vidal, J. (1997): La dinámica comercial romana entre Italia e Hispania Citerior, Alicante: Universidad.

Molina Vidal, J. (1999): "Vinculaciones entre Apulia y el área de influencia de Carthago Nova en la época tardorrepublicana". Latomus, 58/3: 509-524.

Mrabet, A. (2007): In Africa et in Hispania: études surl' huile africaine, [= Col-lecció Instrumenta 25]. Barcelona: Universidad.

Pérez Ballester, J. (2009): "Puertos, rutas y cargamentos: el comercio marítimo en época republicana", en: Arqueologia nàutica mediterrània, M.A. Cau Ontiveros, F.X. Nieto Prieto (eds.). Girona: Centre d'Arqueología Subaquática de Catalunia: 551-566.

Pérez Bonet, M.A. (1989): “Calle Fabrica (Puerto Mazarrón)”. Memorias de Arqueología, 4: 237-243.

Pérez Bonet, M.A. (1992): "El vertedero y la necrópolis tardíos de la c/ San Vicente (Puerto de Mazarrón, Murcia)”. Memorias de Arqueología, 6: 241-249.

Pérez Bonet, M.A., Cabrera Bonet, P. (1992): "Ánforas romanas de origen egeo procedentes del Puerto de Mazarrón (Murcia)". Archivo Español de Arqueología, 65: 308-312.

Pérez Rebollo, F. (1989): “Carta arqueológica submarina de las costas de la región de Murcia. Prospección durante la campaña 1989”. Memorias de Arqueología, 4: 641-654.

Pinedo Reyes, J., Pérez Bonet, M.A. (1991): "El yacimiento subacuático tardorromano de la Cala Reona. Estudio preliminar". Antigüedad y Cristianismo, 8: 391-408.

Quevedo, A., Bombico, S. (2016): "Lusitanian Amphorae in Carthago Nova (Cartagena, Spain): Distribution and Research Questions", en: Lusitanian Amphorae: Production and Distribution, I. Vaz Pinto, R.R. de Almeida, A. Martin (eds.), [= RLAMP Series 10]. Oxford: University: 311-322. 
Ramallo Asensio, S.F. (1985): "Envases para salazón en el Bajo Imperio (I)", en: VI Congreso Internacional de Arqueología Submarina, Cartagena 1982. Madrid: Ministerio de Educación, Cultura y Deporte: 435-442.

Ramallo Asnesio, S.F., Ruiz Valderas, E., Berrocal Caparrós, M.C. (1996): “Contextos cerámicos de los siglos V-VII en Cartagena”. Archivo Español de Arqueología, 69: 135-190.

Ramallo Asensio, S.F., Martínez Andreu, M. (2010): “El puerto de Carthago Nova: eje de vertebración de la actividad comercial en el sureste de la Península Ibérica”. Bollettino di Archeologia: on line vol. speciale B/B7/11: 141-159.

Remolà Vallvedú, J.A. (2000): Las ánforas tardo-antiguas en Tarraco (Hispania Tarraconensis): siglo IV-VII d.C., [= Col-lecció Instrumenta 7]. Barcelona: Universidad.

Reynolds, P. (2011): "A $7^{\text {th }}$ century pottery deposit from Byzantine Carthago Spartaria (south-eastern Spain)", en: LRFW 1 Late Roman fine wares: solving problems of typology and chronology. A review of the evidence debate and new contexts, Roman and Late Antique Mediterranean pottery, M.A. Crau, P. Reynolds, M. Bonifay (eds.). Oxford: University: 99-127.

Roldán Gómez, L. (ed.) (1990): La arqueología subacuática en España. Madrid: Ministerio Educación, Cultura y Deporte. 